\title{
Mecanismos Disciplinadores da Gestão de Custos Interorganizacionais e Economia dos Custos de Transação: um ensaio teórico
}

\section{Resumo}

O presente artigo buscou verificar se os mecanismos disciplinadores, presentes na estrutura conceitual da Gestão de Custos Interorganizacionais (GCI), estão relacionados aos mecanismos de governança previstos pela Economia dos Custos de Transação (ECT), enquanto instrumentos para salvaguardar relações contratuais. $\mathrm{O}$ trabalho foi desenvolvido por meio de um ensaio teórico, com base em pesquisa bibliográfica, tendo como contribuição principal para a literatura, a identificação da existência de relacionamentos entre mecanismos já consolidados da ECT, a qual busca verificar a forma como ocorrem as transações, e os mecanismos recentes da GCI, que busca, por meio do gerenciamento de custos, a otimização do retorno total da cadeia de valor além dos limites da própria empresa. Como conclusão do trabalho constatou-se que, mesmo sendo recente a literatura acerca da GCI, os mecanismos disciplinadores utilizados por este artefato da Gestão Estratégica de Custos vão ao encontro dos mecanismos de governança utilizados pela ECT, ao apresentarem relação e sinergia em diversos dos mecanismos analisados.

Palavras-chave: Gestão de Custos Interorganizacionais: Mecanismos Disciplinadores: Economia dos Custos de Transação.

\author{
Rosimeire Pimentel Gonzaga \\ Doutorado em Controladoria e Contabilidade \\ pela FEA/USP e Professora- Adjunta da \\ Universidade Federal de Minas Gerais. \\ Contato: Avenida Antônio Carlos, 6627, \\ Pampulha. Belo Horizonte (MG). \\ CEP.: 31270-901. \\ E-mail: ropgonzaga@face.ufmg.br
}

Humberto Silva Aillón

Mestre em Controladoria e Contabilidade pela FEA/USP e Diretor de Finanças e Controladoria da Linx S.A. Contato: Rua Cenno Sbright 170, Água Branca. São Paulo-SP. CEP.: 05036-010. E-mail: Humberto.aillon@gmail.com

\section{Lara Cristina Francisco de Almeida Fehr}

Mestre em Administração pela Universidade Federal de Uberlândia - UFU e ProfessoraAssistente na Universidade Federal de Uberlândia. Contato: Avenida João Naves de Ávila, 2121, Bloco F, Sala 203, Santa Mônica. Uberlândia-MG. CEP.: 38400-902.

E-mail: larafehr@facic.ufu.br

\section{Márcio Luiz Borinelli}

Doutorado em Controladoria e Contabilidade pela FEA/USP e Professor Doutor da Universidade de São Paulo - FEA/USP. Contato: Avenida Professor Luciano Gualberto, $n^{0}$ 908, FEA-3, Butantã. São Paulo-SP. CEP.: 05508-010.

E-mail: marciolb@usp.br

\section{Welington Rocha}

Doutorado em Controladoria e Contabilidade pela FEA/USP e Professor Doutor da Universidade de São Paulo- FEA/USP. Contato: Avenida Professor Luciano Gualberto, no 908, FEA-3, Butantã. São Paulo-SP. CEP.: 05508-010.

E-mail:w.rocha@usp.br 


\section{Introdução}

Observa-se, na literatura recente, o surgimento de alguns questionamentos quanto ao real limite da firma, assim como questionado por Coase em 1937. Coase (1937) argumenta que os limites das firmas no mundo real são distintos dos limites definidos pela literatura abordada pela teoria econômica clássica.

Diferentemente da visão da teoria econômica clássica, a firma pode ser definida como um conjunto de contratos coordenados para a execução da função produção, sendo que as relações contratuais entre firmas podem ser configuradas por franquias, alianças estratégicas e parcerias, expandindo o conceito tradicional de firma (Zylberzstajn, 2000). Ainda, Souza e Rocha (2009) argumentam que o nexo de contratos o qual define a firma regula e coordena as interações entre agentes e ativos, envolvidos nas diversas transações e atividades das firmas.

Desse modo, é possível verificar que os limites da firma extrapolam os limites jurídicos e que existem relações contratuais das empresas com agentes ou companhias externas. Alguns autores (Coad \& Cullen, 2006; Menard, 2004) têm ressaltado o crescimento de relações contratuais entre firmas, sendo utilizado para gestão das mesmas ferramentas como alianças estratégicas, integração vertical, entre outras. Nesse contexto, desponta-se a gestão de custos interorganizacionais (GCI) como alternativa para o gerenciamento dos custos nas relações contratuais entre companhias (Souza \& Rocha, 2008).

Assim, a GCI pode ser definida como uma abordagem estrutural de coordenação de atividades nas relações contratuais das empresas, considerando uma rede de fornecimento, proporcionando redução do custo total da rede (Souza \& Rocha, 2009; Hoffjan \& Kruse, 2006).

Para a aplicabilidade da GCI, são requeridos alguns instrumentos considerados como mecanismos de controle organizacionais, sendo esses instrumentos utilizados para condução das organizações envolvidas na GCI. Dentre eles, destacam-se os mecanismos disciplinadores, com a função de reger as relações contratuais de duas ou mais organizações, em uma cadeia de valor (Souza \& Rocha, 2009), e, assim, transmitir as pressões de redução de custos ao longo da cadeia, por meio do estabelecimento de metas para redução de custos (Bhimani, Souza \& Rocha, 2011).

Contudo, os diversos contratos que compõem as firmas são incompletos (Iudícibus \& Lopes, 2004), requerendo custos de manutenção e de se fazer executar os contratos internos e externos das empresas, podendo ser definidos como custo de transação (Rocha, Carvalheiro, Staduto, \& Opazo, 2008).

Para Rocha et al. (2008), as análises dos contratos envolvidos nas diversas relações das empresas têm sido o principal foco da Economia dos Custos de Transação (ECT), dada sua função enquanto gerir ou governar as diversas transações das firmas. Ainda, diante deste cenário de incompletude dos contratos, Sunder (1997) define que a Contabilidade possui algumas funções para a coordenação dos vários contratos existentes, como: i) mensurar a contribuição de cada um dos participantes nos contratos; ii) mensurar a fatia que cada um dos participantes tem direito do resultado da empresa; iii) informar os participantes a respeito do grau de sucesso do cumprimento dos contratos; e iv) distribuir informações como conhecimento comum, para reduzir o custo da negociação dos contratos.

Nessa linha, caso os mecanismos disciplinadores utilizados pela GCI estejam relacionados aos mecanismos de governança das relações contratuais utilizados pela ECT, é possível que esses possam ser utilizados como mecanismos de controle das relações contratuais, requeridos para aplicação da GCI, uma vez que existe uma carência de estudos e modelos conceituais específicos sobre mecanismos a serem utilizados para esse fim, na estrutura da GCI (Souza, 2008). Ainda, evidências empíricas já encontradas na literatura acerca da estrutura de governança da ECT poderiam oferecer subsídios ou elementos que ajudassem nas soluções dos problemas envolvendo a utilização dos mecanismos disciplinadores da GCI.

Diante deste contexto, esta pesquisa fundamenta-se em duas premissas: i) há necessidade de mecanismos de controle nas relações de troca entre firmas, os quais são inerentes à GCI; ii) há necessidade de estruturas de governança para controlar as transações das firmas, em face das incompletude dos contratos, as quais são contempladas pela ECT. Com base nestas premissas, o problema deste estudo, portanto, reside no fato de não se saber, teoricamente, se os mecanismos de controle propostos pela GCI possuem relação com 
os mecanismos de governança da ECT, de tal forma que esta relação, se existente, possa suprir as necessidades estabelecidas nas premissas acima e melhorar os relacionamentos interorganizacionais. Para investigar este problema, formula-se a seguinte questão de pesquisa: Há relação entre os mecanismos disciplinadores presentes na Gestão de Custos Interorganizacionais e os mecanismos de governança previstos na Economia dos Custos de Transação?

Desse modo, o presente trabalho tem como objetivo verificar se os mecanismos disciplinadores presentes na estrutura conceitual da GCI estão relacionados aos mecanismos de governança previstos pela ECT, bem como os instrumentos para salvaguardar relações contratuais.

Para tanto, primeiramente são apresentados os elementos disciplinadores previstos na estrutura conceitual da GCI e, posteriormente, os mecanismos de governança previstos pela ECT. Na visão de Xu (2011), a GCI sofreu fortes influências da ECT e ampliou seu destaque com a Contabilidade Gerencial Estratégica e Análise da Cadeia de Valor.

Nesse sentido, este estudo contribui para a literatura, apresentando evidências quanto à existência de possíveis relacionamentos entre mecanismos de uma teoria que busca verificar a forma como ocorrem as transações, considerando um dado ambiente; e a estrutura de um artefato utilizado para a gestão de custos, considerando diversas relações ao longo de uma cadeia de valor. Outra contribuição do presente estudo é a possibilidade da utilização dos mecanismos já estruturados da ECT para a GCI, com o intuito de aumentar a probabilidade de sucesso na implantação da GCI, dada a carência de instrumentos existentes destinados a gestão dos relacionamentos envolvidos em uma cadeia de valor. Ainda, considerando que a GCI é uma contribuição inovadora para o fomento da competitividade empresarial (Faria, Soares, Rocha \& Rossi, 2013), estudos que possibilitem a identificação de instrumentos que poderiam ser utilizados para aumentar a probabilidade de sucesso da implantação da ferramenta poderiam trazer valiosas contribuições para a literatura gerencial.

Em última instância, caso seja comprovada a relação, além de fazer avançar o conhecimento teórico, buscando integrar dois elementos importantes voltados à gestão das organizações (ECT e GCI), as empresas poderão fazer uso de tais mecanismos de forma integrada, buscando elevar os ganhos nos relacionamentos interorganizacionais e reduzir os custos de transação atrelados a tais relacionamentos.

Este artigo está estruturado em cinco seções, sendo a primeira a presente introdução; na segunda, apresenta-se o referencial teórico acerca da GCI e da ECT; na terceira seção, descreve-se a trajetória metodológica utilizada na investigação; na quarta, discute-se a relação entre os mecanismos disciplinadores previstos pela GCI e os mecanismos de governança previstos pela ECT, considerados como instrumentos para salvaguardar relações contratuais; e na última seção, são apresentadas as considerações finais e sugestões para futuras pesquisas.

\section{Referencial teórico}

Esta seção destina-se a discutir os elementos teóricos que fundamentam as análises desenvolvidas na seção 4. Os principais aspectos sobre a GCI são apresentados, em especial aqueles relativos aos mecanismos disciplinadores das relações entre organizações. Na sequência, além dos principais elementos conceituais que norteiam a ECT, são discutidos os mecanismos de governança previstos nesta teoria.

\subsection{Gestão de Custos Interorganizacionais: aspectos gerais}

Segundo Cooper e Slagmulder (2003), caso ocorra a possibilidade de alguma das partes que compõem a cadeia de valor serem geridas de forma mais eficiente, a cadeia como um todo poderá ser mais lucrativa e, ainda, todas as empresas envolvidas na cadeia poderão ser beneficiadas. 
A cadeia de valor pode ser definida como o conjunto de atividades realizadas pela organização nas relações com fornecedores, ciclo de produção e vendas até a distribuição final (Porter, 1989). Porém, a definição oferecida por Porter (1989) considera a distribuição final como sendo o ultimo estágio da cadeia, considerando apenas o ambiente interno, sendo que a distribuição final não seria necessariamente o final do processo, devendo este ultrapassar os limites internos da própria empresa (Rocha \& Borinelli, 2007).

Para Shank e Govindarajan (1993) a cadeia de valor representa um conjunto interligado de todas as atividades que criam valor para o processo produtivo como um todo, englobando as operações compreendidas desde a aquisição da matéria-prima à entrega do produto final aos consumidores. Entretanto, Shank e Govindarajan (1993) desconsideram a existência de possíveis atividades de pós-vendas como integrante da cadeia de valor, revelando certa fragilidade na definição.

Rocha e Borinelli (2007) avançam ao definir a cadeia de valor como uma sequência lógica de atividades, com início na origem dos recursos e finalização no descarte do produto pelo consumidor. Para os autores, a análise da cadeia de valor oferece suporte para o processo de gestão estratégica das estruturas patrimonial, econômica, financeira e operacional das suas principais atividades, processos e entidades. Todavia, nessa definição não é explícita a ideia de relacionamentos e, ainda, não há definição clara de quem desempenha as atividades inseridas ao longo da cadeia.

Assim, por meio de uma análise basilar das definições apresentadas, é possível inferir que a análise da cadeia de valor refere-se a uma sequência lógica de atividades inter-relacionadas, em que, a cada elo, insumos, trabalho e capital são transformados para criação de valor, desde a origem dos recursos até a destinação final dada pelo último consumidor.

Nesse sentido, desponta-se a GCI com a função de gerir os custos por meio de um processo cooperativo ao longo de uma cadeia produtiva ou cadeia de valor, incluindo, em seu escopo de atuação objetos compreendidos além dos limites da própria firma (Souza \& Rocha, 2009).

A GCI pode ser definida como uma abordagem estruturada acerca da coordenação das atividades das empresas incluídas em uma cadeia de valor, resultando em redução dos custos envolvidos ao longo de toda uma rede de fornecimento (Cooper \& Slagmulder, 1999; Hoffan \& Kruse, 2006). Contudo, segundo Souza e Rocha (2008), o escopo da GCI vai além da rede de fornecimento, conforme destacado por Cooper e Slagmulder (1999) e Hoffjan e Kruse (2006). Dessa forma, é possível se inferir que a GCI compreende um processo cooperativo que, por meio do gerenciamento de custos, visa à otimização do retorno total da cadeia de valor, além do retorno da própria empresa.

Para a implantação da GCI, é necessária a utilização de alguns mecanismos que ofereçam suporte para a troca de informações entre os integrantes de toda a cadeia de valor, como o open-book accounting ou abertura de livros (Cooper \& Slagmulder, 2003; Kajüter \& Kumala, 2005; Souza \& Rocha, 2009). Kajüter e Kumala (2005) descrevem o conceito de open-book accounting como um instrumento utilizado para o compartilhamento de informações relacionadas aos custos envolvidos nos processos produtivos.

Como a transparência das estruturas de custos pode ser um importante elemento para que surjam oportunidades de redução de custos, por meio de esforços em conjunto dos membros da cadeia, a prática do open-book accounting assume importante função em termos de apoio à aplicação da GCI (Cooper \& Slagmulder, 1999; Dekker, 2003; Coad \& Cullen, 2006; Agndal \& Nilsson, 2010), visto que pode melhorar a eficiência de custos na cadeia e estabelecer confiança no relacionamento de parceria entre comprador e fornecedor (Kajüter \& Kumala, 2005).

Por um lado, Windolph e Möller (2012) argumentam sobre como o open-book accounting tem sido utilizado como meio de manutenção do controle das atividades terceirizadas e de aumento da eficiência na cadeia de suprimentos. Por outro lado, os autores encontraram que o open-book accounting pode afetar negativamente o relacionamento com o fornecedor, representando um risco potencial para processos de cooperação. Os resultados sugerem, ainda, que algumas ferramentas podem ser utilizadas para salvaguardar comportamentos oportunistas, diminuindo o efeito negativo do open-book accounting. 
Segundo Souza e Rocha (2009), a GCI não é um processo espontâneo, e sua aplicação envolve alguns aspectos contingenciais exógenos (variáveis ambientais) ou endógenos à cadeia de valores (variáveis específicas da cadeia), ou ainda, específicos da organização (aspectos da entidade), sendo esses denominados como fatores condicionantes. Ademais, além dos fatores condicionantes as empresas precisam definir quais mecanismos de controle da GCI serão utilizados, podendo ser definidos enquanto mecanismos capacitadores, incentivadores e disciplinadores (Souza \& Rocha, 2009).

Os mecanismos capacitadores buscam auxiliar as empresas envolvidas na cadeia a encontrarem formas de harmonizarem habilidades juntamente e coordenarem os esforços envolvidos no processo de produção, como meio para alcançarem, coletivamente, a otimização de custos, como, por exemplo, a gestão baseada em atividades, treinamentos interorganizacionais, entre outros (Aguiar, Rezende \& Rocha, 2008; Souza \& Rocha, 2009).

Ainda, os mecanismos incentivadores podem ser definidos como ferramentas que "[...] gratificam as partes, utilizados posteriormente ao alcance de metas estipuladas, para premiar e remunerar pelo objetivo alcançado; podem ser monetários (bônus por alcance de metas) ou não monetários (garantia de relacionamentos no curto prazo)" (Souza \& Rocha, 2008, p. 98).

Por fim, os mecanismos disciplinadores buscam comunicar as forças existentes voltadas à otimização de custos ao longo de toda a cadeia (Aguiar, Rezende \& Rocha, 2008; Cooper \& Slagmulder, 1999), conforme descrito no próximo tópico.

\subsection{Mecanismos Disciplinadores da Gestão de Custos Interorganizacionais}

Para aumentar a probabilidade de sucesso na implementação da GCI, faz-se necessária a análise de cinco fatores considerados importantes elementos do processo: (i) produto; (ii) componentes dos produtos; (iii) nível de relacionamento; (iv) categorias da cadeia de valor; e (v) mecanismos de governança. Entre os mecanismos de governança existentes, estão os mecanismos disciplinadores, que, além de gerar maior controle onde existe a necessidade de governança, criam regras para controle das ações e recompensas entre organizações, com base nas obrigações contratadas entre as partes (Bhimani et al., 2011).

Ainda que os mecanismos disciplinadores tenham a utilidade de controle organizacional, vale ressaltar que não se restringem apenas à aplicação de penalidades, possuindo escopo mais amplo, tendo as finalidades de prevenir, evitar ou conter ilegalidade, abuso, desvios de conduta e transgressões às regras estipuladas (Camacho, 2010).

Na visão de Slagmulder (2002), um dos mecanismos disciplinadores existentes é o custeio alvo, uma vez que propicia otimização de custos de produtos e componentes entre fornecedores e clientes. Além do custeio alvo, existem outros mecanismos, como os protocolos de rede e orçamentos interorganizacionais. Corroborando essa visão, Mouritsen, Hansen e Hansen (2001) reforçam que o custeio alvo é um mecanismo de controle gerencial que foca na gestão do desenvolvimento e design de processos.

Souza (2008) observou em duas cadeias de organizações distintas, a existência de dois tipos de mecanismos disciplinadores, sendo eles a abertura de livros e contratos de nível de serviço, ambos com a finalidade de disciplinar o relacionamento entre os agentes. Em linha oposta, para Camacho (2010), a abertura de livros é classificada como mecanismo capacitador da GCI e não um mecanismo disciplinador, como mencionado por Souza (2008). Quanto ao propósito dos mecanismos disciplinadores, Souza (2008), corroborando a visão de Cooper e Slagmulder (1999), define que sua função é auxiliar as empresas a alcançarem a meta estipulada. Sendo assim, também alcança a meta prevista para a cadeia de valor.

Camacho (2010) verificou que acordos formais de sigilo ou confidencialidade de informações podem ser firmados entre fornecedor e clientes, com a finalidade de suprir ou promover a confiança, reforçando que, com a ausência desses mecanismos disciplinadores, a adoção da GCI torna-se pouco provável. 
A adoção dos mecanismos disciplinadores, como a adoção formal de contratos, acordos de confidencialidade de informações, orçamentos interorganizacionais e custeio alvo, impulsionam a GCI, pois reduzem as possibilidades de: i) ser explorado pelo parceiro, no caso de divulgação de informações da estrutura de custos; ii) ser abandonado pelo parceiro, no caso de não atingimento das metas de otimização de custos; iii) ter seus custos divulgados pelo parceiro ao concorrente; iv) não ocorrer divisão dos ganhos gerados pela GCI (Dekker, 2003; Kajüter \& Kulmala, 2005).

Mouritsen et al. (2001) realizaram uma análise com base em duas empresas que terceirizaram grande parte do seu processo, mas que, em curto prazo, experimentaram evasão de conhecimento, perda de transparência e controle. Como resultado para superação dessa situação, ambas as empresas investiram na gestão do processo interorganizacional, tendo uma delas focado no custeio alvo e a outra empresa, optado pela abertura de livros. Com base nos estudos citados, é possível afirmar que, para o aumento da probabilidade da adoção da GCI, são necessários contratos em sua essência; caso contrário, não será atingido o processo cooperativo, que, por meio do gerenciamento de custos, busca a otimização do retorno total da cadeia de valor, extrapolando os limites além da própria empresa.

Para Vosselman e Merr-Kooitra (2009), a confiança sempre é associada ao controle e ambos possuem uma expectativa em comum: o estabelecimento e a manutenção de expectativas positivas de comportamento. Todavia, efetivas práticas de controle podem ser resultantes de uma estrutura de governança que negocia acordos entre as partes, sendo que tais práticas podem implicar formas instrumentais de prestação de contas, que podem ser sistemas de mensuração de desempenho, custeio alvo, sistemas de gestão de custos e sistemas de incentivo financeiros.

Nesse sentido, o custeio alvo aparece como um mecanismo disciplinador, em função de ser, primeiramente, uma técnica para gestão de rentabilidade, permitindo a identificação de quanto deverá ser o custo de um produto, antes mesmo de ser produzido, e, adicionalmente, pela visão micro do custo alvo, abrangendo até o nível de componente. Ainda, estes objetivos podem ser utilizados com o intuito de gerar pressão nos fornecedores, para que ocorra redução de custo com a contratação de custos alvo ao longo da cadeia de valor (Cooper \& Slagmulder, 1997).

Contudo, dada a relevância dos mecanismos disciplinadores para a aplicação da GCI e a existência de um número limitado de mecanismos disciplinadores a serem utilizados, bem como resultados acerca de seus efeitos sobre os relacionamentos envolvidos na GCI, fazem-se necessárias discussões sobre outros mecanismos que poderiam ser utilizados para essa função, advindos de outras correntes teóricas. Nesse sentido, discussões sobre os mecanismos de governança presentes na estrutura da ECT podem apresentar novos elementos, a serem utilizados para gestão dos relacionamentos alvos da GCI.

\subsection{Economia dos custos de transação}

Integrante da linha científica que possui as estruturas de governança como objeto de análise, a ECT busca analisar as transações das instituições, considerando elementos do ambiente onde ocorrem. Assim, operações envolvendo negociações de direitos de propriedade, bens e serviços, bem como os custos a elas associados, sendo esses considerados como indutores dos modos alternativos de governança, são exemplos de elementos da ECT (Zylbersztajn, 1995).

A teoria dos Custos de Transação teve como um de seus percussores Ronald Coase, com a publicação do trabalho intitulado "The Nature of the Firm", em 1937. Coase (1937) buscou verificar os limites e a origem do crescimento das firmas, afirmando que as empresas buscam crescer ponderando os custos de transação da produção internamente, ou da aquisição via mercado.

Ainda, Coase (1959) chamou atenção para o custo de transação presente na literatura econômica, definindo-o como o custo de utilização de mecanismos de preços. Arrow (1969) amplia essa definição, ao 
considerar o custo de transação como o custo de movimentação do sistema econômico. Posteriormente, Williamson (1985) evolui os conceitos existentes, definindo os custos de transação como sendo aqueles relacionados ao planejamento e monitoramento, das estruturas de governança.

Nesse ínterim, a teoria dos Custos de Transação ganhou relevo com os trabalhos de Williamson (1975; 1981; 1985) ao destacar as seguintes formas organizacionais ou estruturas de governança existentes: i) estrutura de mercado, que ocorre por meio de sistemas de preços, implicando em maiores incentivos e menores níveis de controle; ii) estrutura hierárquica ou firma, centrando-se nas propriedades dos ativos envolvidos nas transações e a questão da internalizações das atividades; e iii) estrutura híbrida, também denominada contratos, a qual se baseia nas relações contratuais e arranjos propriedades na cadeia produtiva.

Assim, os mecanismos de governança são regras e normas formais ou informais utilizadas com o intuito de se obter a eficácia da transação (Williamson, 1996). Sob a ótica da ECT, as partes envolvidas nas relações contratuais podem não possuir capacidade para previsão do comportamento de todas as partes envolvidas e, ainda, há a possibilidade de ocorrência de possíveis mudanças no ambiente institucional. Nesse sentido, os integrantes da relação contratual podem utilizar-se de instrumentos, como os mecanismos de governança, para redução dos riscos relacionados ao comportamento oportunista dos agentes envolvidos.

Ademais, os mecanismos de governança ou arranjos contratuais são utilizados para dirimir o risco contratual envolvido nas transações e, consequentemente, diminuir o custo de transação. Nesse sentido, os riscos envolvidos variam de acordo com os atributos e características da transação, considerando os pressupostos de oportunismo e racionalidade limitada dos agentes (Muniz, Aquino \& Pagliarussi, 2007).

Contudo, segundo Williamson $(1985,1996)$, para escolha dos mecanismos de governança a serem utilizados, é necessário considerar a natureza das relações. Williamson (1985) identificou três atributos principais inerentes à natureza das transações, quais sejam: i) frequência da transação; ii) incerteza relativa à transação; e iii) especificidade dos ativos envolvidos na transação.

Com relação à frequência da transação, essa está relacionada à recorrência de determinada transação, em que maior frequência de ocorrência da transação resulta em menores custos fixos médios. Assim, as partes envolvidas poderiam desenvolver reputação nas transações recorrentes, limitando o comportamento oportunista dos agentes, para obtenção de ganhos no curto prazo (Arruda, 2014, Farina, 1999).

A incerteza está relacionada à incapacidade de os agentes prevenirem acontecimentos futuros, gerando aberturas para renegociações. Assim, maiores possibilidades de renegociação gerariam maior possibilidade de perdas em função do comportamento oportunista das partes e possíveis desentendimentos entre elas (Farina, 1999). Ainda, a racionalidade limitada dos agentes, a incompletude dos contratos e o comportamento oportunista dos agentes estão relacionados ao nível de incerteza das transações (Arrow, 1974).

A especificidade dos ativos envolvidos nas transações refere-se à possibilidade de utilização alternativa de determinado ativo em detrimento da opção principal ou original, sem perda do valor produtivo do ativo (Britto, 1994). Segundo Farina (1999), a especificidade do ativo está relacionada ao grau de dependência de determinado ativo em relação à continuidade de uma transação específica, considerando que quanto maior o nível de especificidade do ativo, maior a possibilidade de perdas em função de comportamentos oportunistas de outros agentes, gerando maiores custos de transação.

Em adição, nesse contexto é necessário se considerar dois pressupostos comportamentais: a racionalidade limitada e o oportunismo dos agentes, uma vez que, oferecem sustentação para explicação dos custos de transação e das estruturas de governança. A racionalidade limitada se refere ao fato de que, apesar de os agentes possuírem comportamento otimizador, eles não conseguem otimizá-lo completamente nas relações contratuais em função da incompletude dos contratos. Já o oportunismo está relacionado ao fato de os agentes agirem de forma a promover a obtenção de vantagens nas transações (Zylbersztajn, 1995).

A existência de oportunismo e racionalidade limitada podem aumentar o nível de incerteza e, consequentemente, elevar os riscos e custos das transações (Miranda, Mendes, Souza \& Zuccolotto, 2010). Ainda, o oportunismo pode resultar em perdas consideráveis para os agentes, justificando a adoção de mecanismos de monitoramento e controle e cláusulas de salvaguardas dos contratos envolvidos nas transações (Williamson, 1985). 


\section{Aspectos metodológicos}

O objetivo do presente trabalho é verificar se os mecanismos disciplinadores presentes na estrutura conceitual da GCI estão relacionados aos mecanismos de governança previstos pela ECT, como instrumentos utilizados para salvaguardar as relações contratuais.

Para alcançar o objetivo proposto utilizou-se do método definido como ensaio teórico, com base em pesquisa bibliográfica, uma vez que se desenvolve uma proposta a respeito de um determinado tema a partir da análise de trabalhos já desenvolvidos (Santos, 1999). Este método oferece maior liberdade ao autor para defender determinada posição, pois consiste em uma exposição lógica e reflexiva por meio de rigorosa argumentação, interpretação e julgamento pessoal (Severino, 2007). Nesta perspectiva, um ensaio teórico possibilita que os autores indiquem contribuições a partir dos estudos analisados e de suas constatações.

Quanto à pesquisa bibliográfica, essa é baseada em referências como livros, teses, dissertações, artigos, publicações em periódicos, entre outras fontes (Martins, 2000; Vergara, 2003).

Desse modo, é verificada a possível existência de relações entre as definições, características, objetivos e funções dos mecanismos disciplinadores presentes na estrutura da GCI evidenciados na literatura acerca do tema, e as características dos mecanismos de governança presentes na estrutura da ECT. Para tanto, é realizada análise de conteúdo das descrições referentes aos mecanismos disciplinadores presentes na GCI, e dos mecanismos de governança elencados pela ECT, buscando encontrar similaridades entre os itens, como: definição, características, objetivos e funções dos objetos de análise.

Com relação aos tipos de governança a serem analisados, bem como suas características, serão utilizados como base os tipos de governança descritos pela literatura e as principais caraterísticas, conforme levantadas por Peres (2007), de acordo com o Quadro 1:

\begin{tabular}{cl}
\hline $\begin{array}{c}\text { Estrutura de } \\
\text { Governança }\end{array}$ & Características \\
\hline Mercado & $\begin{array}{l}\text { Neste tipo de estrutura de governança, os incentivos são fortes e o ajuste se dá via preços. Há } \\
\text { pouca necessidade de controles administrativos e os contratos são cumpridos sem riscos de } \\
\text { comportamento oportunista. }\end{array}$ \\
\hline Híbrida & $\begin{array}{l}\text { Nesta estrutura, os incentivos são médios, visto que existem falhas de mercado que } \\
\text { impossibilitam ajustes autônomos via preço. É, então, necessária a coordenação dos indivíduos } \\
\text { dentro de sistemas de incentivos e contratos que coíbam o comportamento oportunista e } \\
\text { possam reduzir os custos de transação em ambiente de informação assimétrica. }\end{array}$ \\
\hline Hierárquica & $\begin{array}{l}\text { Na estrutura hierárquica, os incentivos são fracos e existe forte impacto das falhas de mercado, } \\
\text { a ponto de prejudicar o cumprimento de contratos sujeitos sempre à ação oportunista dos } \\
\text { agentes. Neste ambiente, a barganha pode ser ineficiente e há necessidade de coordenação e } \\
\text { imposição da autoridade política para a busca de resultados eficientes. }\end{array}$ \\
\hline
\end{tabular}

Quadro 1. Estruturas de Governança

Nota: Peres (2007, p. 20)

Quanto aos elementos a serem analisados, referentes aos mecanismos disciplinadores da GCI, serão considerados aqueles mecanismos destacados pela literatura referenciada ao longo do presente estudo, bem como suas principais características referenciadas no Quadro 2 que segue: 


\begin{tabular}{|c|c|c|}
\hline Autores & Mecanismos & Características \\
\hline \multirow{3}{*}{$\begin{array}{l}\text { Slagmulder } \\
(2002)\end{array}$} & Custeio alvo & \multirow{3}{*}{$\begin{array}{l}\text { Propiciam otimização de custos de produtos e componentes } \\
\text { entre os fornecedores e clientes; geram pressão nos } \\
\text { fornecedores. }\end{array}$} \\
\hline & Protocolos de rede & \\
\hline & Orçamentos interorganizacionais & \\
\hline \multirow{2}{*}{ Souza (2008) } & Abertura de livros & \multirow{2}{*}{$\begin{array}{l}\text { Disciplinam o relacionamento entre os agentes; propiciam o } \\
\text { compartilhamento de informações; geram controle de atividades. }\end{array}$} \\
\hline & Contratos de nível de serviço & \\
\hline Camacho (2010) & $\begin{array}{l}\text { Acordos formais de sigilo entre } \\
\text { fornecedor e cliente }\end{array}$ & Supre ou promove a confiança. \\
\hline \multirow{4}{*}{$\begin{array}{l}\text { Dekker (2003), } \\
\text { Kajüter e } \\
\text { Kulmala (2005) }\end{array}$} & Adoção formal de contratos & \multirow{4}{*}{$\begin{array}{l}\text { Reduzem a possibilidade de (i) ser explorado pelo parceiro, no } \\
\text { caso de divulgação de informações da estrutura de custos; (ii) } \\
\text { ser abandonado pelo parceiro, no caso de não atingimento das } \\
\text { metas de otimização de custos; (iii) ter seus custos divulgados } \\
\text { pelo parceiro ao concorrente; e (iv) não ocorrer divisão dos } \\
\text { ganhos gerados pela GCl. }\end{array}$} \\
\hline & $\begin{array}{l}\text { Acordos de confidencialidade de } \\
\text { informações }\end{array}$ & \\
\hline & Orçamentos interorganizacionais & \\
\hline & Custeio alvo & \\
\hline \multirow{4}{*}{$\begin{array}{l}\text { Vosselman e } \\
\text { Merr-Kooitra } \\
(2009)\end{array}$} & $\begin{array}{l}\text { Sistemas de mensuração de } \\
\text { desempenho }\end{array}$ & \multirow{4}{*}{$\begin{array}{l}\text { Resultam de uma estrutura de governança que negocia um } \\
\text { acordo entre as partes; constituem formas instrumentais de } \\
\text { prestação de contas. }\end{array}$} \\
\hline & Sistemas de gestão de custos & \\
\hline & Sistemas de incentivo financeiros & \\
\hline & Custeio alvo & \\
\hline
\end{tabular}

Quadro 2. Mecanismos Disciplinadores da GCI

Nota: elaborado pelos autores.

Desse modo, espera-se encontrar relação entre os mecanismos de governança utilizados pela ECT, os quais buscam verificar a forma como ocorrem as transações, e os mecanismos disciplinadores presentes na GCI, os quais buscam, por meio do gerenciamento de custos, a obtenção da otimização do retorno total da cadeia de valor além da própria empresa.

\section{Relacionamento entre mecanismos disciplinadores da GCI e mecanismos de governança da ECT}

Mecanismos gerenciais voltados para o planejamento e controle são utilizados como base para sustentação da GCI, ou seja, viabilizam a aplicação da GCI, utilizando-se de alguns instrumentos de controle, incentivo e orientação (Mouritsen et al., 2001; Souza \& Rocha, 2009). Entre eles, os mecanismos disciplinadores visam reger as relações contratuais de duas ou mais organizações, estabelecendo metas de comportamento e pressões nos relacionamentos.

A aplicabilidade da GCI está sustentada na existência de alguns pressupostos, como: abertura de livros; busca da melhoria na gestão de custos ao longo de toda a cadeia; e ferramentas que viabilizem a construção de confiança entre os agentes nos relacionamentos e transações (Aguiar, Rezende \& Rocha, 2008).

Dado que para a implantação da GCI é previsto, então, que existam relacionamentos entre os agentes envolvidos nas transações, que podem ocorrer ao longo da cadeia, faz-se necessária a utilização de mecanismos que possam reger tais relações. Ainda, conforme previstos pela ECT, inerente às transações ocorridas ao longo da cadeia, encontram-se o oportunismo e a racionalidade limitada dos agentes, podendo aumentar o risco e os custos de transações, justificando a adoção de mecanismos que possam reduzir os custos de transação (Miranda et al., 2010; Zylbersztajn, 1995). 
Por um lado, na estrutura utilizada pela GCI, os mecanismos disciplinadores têm como função “[...] prevenir, evitar ou conter a ilegalidade, os desvios de conduta, as transgressões às regras estipuladas e, consequentemente, evitar penalidades" (Souza \& Rocha, 2009, p. 97). Por outro lado, sob a ótica da ECT, os mecanismos utilizados para dirimir os custos de transação envolvidos nas relações contratuais são os mecanismos de governança (Williamson, 1996).

Assim, nesta seção, busca-se entender os possíveis aspectos em que os mecanismos ligados a esses dois elementos conceituais (GCI e ECT) podem se relacionar. Para isso, e por se tratar de um ensaio teórico, a análise se dá cotejando os mecanismos de um e de outro, buscando encontrar similaridades, complementariedades e afinidades de objetivos. Nesse sentido, a análise se dá levando-se em conta os seguintes aspectos: a) níveis de controle; 2) níveis de incentivos; e c) existência de comportamento oportunista.

Para melhor entendimento da análise, a apresentação é feita por tipo de mecanismo de governança previsto na ECT.

\section{a) Estrutura de mercado}

Com relação ao mecanismo de governança descrito, enquanto estrutura baseada em mercado, sabe-se que este tem um controle menor sobre o comportamento dos agentes e utiliza-se de fortes incentivos para minimizar os custos de transação (Peres, 2007; Williamson, 1985). Ademais, há menos riscos de comportamento oportunista.

Nesse sentido, na estrutura conceitual da GCI, os sistemas de incentivos financeiros, de mensuração de desempenho e de gestão de custos são utilizados como integrantes de uma estrutura de governança, que considera a confiança relacionada ao controle e busca a negociação de acordo entre os agentes, a fim de estreitar as relações dos agentes, de forma a minimizar os custos da relação por meio de maior obtenção de controle (Vosselman \& Merr-Kooitra, 2009), conforme previsto pela ECT.

Ainda, tais mecanismos da GCI se constituem em instrumentos formais de prestação de contas, podendo fazer viabilizar a estrutura de governança denominada estrutura de mercado.

Com base nisso, é possível inferir que os mecanismos disciplinadores da GCI podem ser os instrumentos necessários para o funcionamento da estrutura de mercado da ECT, sendo possível perceber relação entre eles.

\section{b) Estrutura híbrida}

A estrutura híbrida está relacionada à busca de coordenação dos agentes por meio de incentivos e contratos, que contém racionalidade limitada e oportunismo dos agentes (Williamson, 1985). Como evidenciado no Quadro 1, nessa estrutura os incentivos são médios, dada a existência de falhas de mercado que inibem ajustes autônomos via preços. Portanto, trata-se de ambiente com informação assimétrica e maior necessidade de coordenação entre indivíduos e contratos que coíbam o comportamento oportunista.

Na visão da GCI, mecanismos como abertura de livros e contratos em nível de serviços buscam coordenar ou disciplinar o relacionamento dos agentes (Souza, 2008). Uma das funções da abertura de livros é que agentes desenvolvam confiança mútua, viabilizando a troca de informações. Ainda, a abertura de livro busca conter comportamento oportunista pelas partes, uma vez que ele poderia destruir qualquer tipo de ação conjunta entre os agentes ao longo da cadeia (Aguiar, Rezende \& Rocha, 2008), ou seja, ela pode ser utilizada como um meio de manutenção do controle das atividades terceirizadas para aumentar a eficiência na cadeia de suprimentos (Windolph \& Moeller, 2012). 
Em complemento, ferramentas como acordos formais de sigilo entre fornecedor e cliente, adoção formal de contratos, acordos de confidencialidade de informações e orçamentos interorganizacionais buscam a geração de confiança entre os agentes e, ainda, dirimir risco de expropriação pela outra parte relacionada (Camacho, 2010; Dekker, 2003; Kajüter \& Kulmala, 2005), promovendo a coordenação dos agentes e diminuindo a possibilidade de ocorrência de comportamentos disfuncionais, conforme previsto pela ECT (Muniz et al., 2007; Williamson, 1996).

Para Coad e Cullen (2006), geralmente, a confiança permite transações que para serem concluídas seriam necessários arranjos hierárquicos por uma rede de organizações parceiras. As vantagens das operações de mercado, tais como incentivos de eficiência, são preservadas, enquanto os benefícios de hierarquia, tais como partilha de conhecimentos e menor necessidade de controles contratuais, também são atingidos. Ainda em seu estudo, os autores concluíram que a implantação da GCI é facilitada pela confiança entre os participantes da cadeia, clientes e fornecedores.

Destaque-se ainda que, como foi visto na seção 2 (referencial teórico), além de gerar mais controle onde existe a necessidade de governança (como é o caso da ECT), os mecanismos da GCI criam regras para controle das ações e formas de recompensas entre as organizações participantes com base nas obrigações previamente contratadas.

Portanto, pela análise acima, pode-se inferir que os mecanismos disciplinadores da GCI descritos, se adequadamente implementados, podem ser os instrumentos necessários para o funcionamento da estrutura híbrida da ECT, uma vez que tendem a coordenar e controlar as relações, reduzir a assimetria de informações e reduzir o comportamento oportunista. Assim, também aqui é possível perceber relação entre os mecanismos da GCI e da ECT.

\section{c) Estrutura hierárquica}

$\mathrm{Na}$ estrutura conhecida como hierarquia, existem falhas de mercado capazes de inviabilizar o cumprimento dos contratos e, diferentemente da estrutura de mercado, institucionalizam-se compromissos em longo prazo (Miller, 1992; Peres, 2007). Conforme se pôde observar no Quadro 1, nessa estrutura, o comportamento oportunista tende a ser ainda mais presente; a barganha entre as partes pode ser menos eficiente e, portanto, há a necessidade de coordenação e imposição de autoridade para o sucesso das relações ao longo da cadeia.

Nesse sentido, o custeio alvo, utilizado como um dos mecanismos disciplinadores pela GCI, entre outros propósitos, busca a redução de custos e o estabelecimento de como as metas referentes à redução de custos devem ser distribuídas entre as empresas integrantes da cadeia, estabelecendo compromissos quanto à redução de custos ao longo do tempo (Cooper \& Slagmulder, 1999). É, também, um instrumento com características de gerar pressão entre os membros da cadeia.

Ademais, o orçamento interorganizacional busca estabelecer compromissos para os agentes integrantes da cadeia, a partir de metas estipuladas, remetendo à institucionalização de compromissos em longo prazo, descrita na estrutura da ECT. O estabelecimento de metas para os agentes, portanto, é uma forma de coordenação de objetivos entre as partes contribuindo para a redução do comportamento oportunista,

Assim, é possível inferir que o custeio alvo e o orçamento interorganizacional são mecanismos disciplinadores da GCI capazes de atender às características da estrutura denominada hierárquica da ECT, mostrando, mais uma vez, a possibilidade de relação entre as partes.

Em suma, de forma geral, os pontos listados no Quadro 3, a seguir, são também capazes de evidenciar a relação existente entre os mecanismos disciplinadores da GCI e as estruturas de governança da GCI: 


\begin{tabular}{|c|c|}
\hline \multirow{6}{*}{$\begin{array}{l}\text { Na Economia de Custos } \\
\text { de Transação, }\end{array}$} & o objetivo é gerir ou governar as diversas transações entre organizações; \\
\hline & os contratos que regem as relações entre as firmas são incompletos; \\
\hline & para fazer cumprir os contratos incorrem-se em custos de transação; \\
\hline & $\begin{array}{l}\text { os custos de transação decorrem das escolhas entre fazer internamente ou adquirir via } \\
\text { mercado; }\end{array}$ \\
\hline & $\begin{array}{l}\text { os custos de transação são os custos de planejamento e monitoramento das estruturas/ } \\
\text { mecanismos de governança dos relacionamentos entre organizações; }\end{array}$ \\
\hline & $\begin{array}{l}\text { os mecanismos de governança são regras e normas formais ou informais utilizadas com } \\
\text { o intuito de se obter a eficácia da transação entre firmas, (i) evitando comportamentos } \\
\text { indesejados (oportunistas); (ii) prevenindo-se em relação a mudanças ambientais; } \\
\text { (iii) dirimindo os riscos contratuais; e, consequentemente, (iv) reduzindo os custos de } \\
\text { transação. }\end{array}$ \\
\hline \multirow{6}{*}{$\begin{array}{l}\text { Na Gestão de Custos } \\
\text { Interorganizacionais, }\end{array}$} & $\begin{array}{l}\text { os mecanismos disciplinadores visam reger as relações contratuais entre duas os mais } \\
\text { organizações; }\end{array}$ \\
\hline & $\begin{array}{l}\text { busca-se mensurar a contribuição de cada um dos participantes nos contratos, bem } \\
\text { como a fatia do resultado a que cada um tem direito; }\end{array}$ \\
\hline & busca-se informar os participantes sobre o grau de cumprimento dos contratos; \\
\hline & $\begin{array}{l}\text { busca-se distribuir informações para reduzir a assimetria informacional e reduzir o custo } \\
\text { da negociação dos contratos e, consequentemente, os custos de transação; }\end{array}$ \\
\hline & os mecanismos disciplinadores possuem a utilidade de controle entre as partes; \\
\hline & $\begin{array}{l}\text { os mecanismos disciplinadores não se restringem ao caráter punitivo mas, também, } \\
\text { visam prevenir, evitar ou conter ilegalidades, abusos e desvios de conduta. }\end{array}$ \\
\hline
\end{tabular}

Quadro 3. Pontos de convergência entre mecanismos disciplinadores da GCl e mecanismos de governança da ECT Nota: elaborado pelos autores.

Portanto, os custos de transação dos contratos entre organizações, firmados à luz da ECT, podem ser reduzidos mediante a utilização dos mecanismos disciplinadores da GCI.

Com base nessas discussões, no Quadro 4, a seguir, são sumarizadas as principais relações encontradas entre os mecanismos disciplinadores da GCI e os mecanismos de governança da ECT. Deve-se ressaltar, no entanto, que, ainda que a análise tenha buscado relacionar "grupos de mecanismos disciplinadores" com cada tipo de mecanismo de governança, esta relação não é exaustiva. Isso quer dizer que, por exemplo, o custeio alvo pode estar relacionado com outras formas de estrutura e não apenas com a hierárquica. Essa opção de relacionamento se deu buscando se verificar onde a relação tende a ser mais forte. 


\begin{tabular}{|c|c|c|c|c|}
\hline \multicolumn{2}{|c|}{ Mecanismos de Governança (ECT) } & \multicolumn{2}{|c|}{ Mecanismos Disciplinadores (GCI) } & \multirow{4}{*}{$\begin{array}{l}\text { Relação entre ECT x GCI } \\
\text { Negociações entre os } \\
\text { agentes, a fim de estreitar } \\
\text { as relações e minimizar os } \\
\text { custos da relação por meio } \\
\text { de maior controle, conforme } \\
\text { previsto pela ECT. }\end{array}$} \\
\hline \multirow{3}{*}{ Mercado } & \multirow{3}{*}{$\begin{array}{l}\text { Menor controle sobre o } \\
\text { comportamento dos agentes } \\
\text { e utilização de incentivos } \\
\text { para minimizar os custos de } \\
\text { transação. }\end{array}$} & Sistema de incentivos & \multirow{3}{*}{$\begin{array}{l}\text { Integram uma } \\
\text { estrutura de } \\
\text { governança } \\
\text { que considera } \\
\text { a confiança } \\
\text { relacionada ao } \\
\text { controle. }\end{array}$} & \\
\hline & & $\begin{array}{l}\text { Sistema de mensuração } \\
\text { de desempenho }\end{array}$ & & \\
\hline & & $\begin{array}{l}\text { Sistema de gestão de } \\
\text { custos }\end{array}$ & & \\
\hline \multirow{6}{*}{ Híbrida } & \multirow{6}{*}{$\begin{array}{l}\text { Prevê a coordenação } \\
\text { dos agentes por meio de } \\
\text { incentivos e contratos que } \\
\text { contemplem questões como } \\
\text { a racionalidade limitada e o } \\
\text { oportunismo dos agentes. }\end{array}$} & Abertura de livros & \multirow{6}{*}{$\begin{array}{l}\text { Coordenam e } \\
\text { disciplinam o } \\
\text { relacionamento } \\
\text { entre agentes } \\
\text { para suprirem } \\
\text { ou promoverem } \\
\text { confiança. }\end{array}$} & \multirow{6}{*}{$\begin{array}{l}\text { Manutenção do controle das } \\
\text { atividades terceirizadas para } \\
\text { aumentar a eficiência na } \\
\text { cadeia de suprimentos. } \\
\text { Geração de confiança entre } \\
\text { os agentes e ainda, dirimir } \\
\text { risco de expropriação pela } \\
\text { outra parte relacionada. } \\
\text { Promoção da coordenação } \\
\text { dos agentes e diminuição da } \\
\text { possibilidade de ocorrência } \\
\text { de comportamentos } \\
\text { disfuncionais, conforme } \\
\text { previsto pela ECT. }\end{array}$} \\
\hline & & $\begin{array}{l}\text { Contratos de nível de } \\
\text { serviço }\end{array}$ & & \\
\hline & & $\begin{array}{l}\text { Acordos formais de } \\
\text { sigilo entre fornecedor e } \\
\text { cliente }\end{array}$ & & \\
\hline & & $\begin{array}{l}\text { Adoção formal de } \\
\text { contratos }\end{array}$ & & \\
\hline & & $\begin{array}{l}\text { Acordos de } \\
\text { confidencialidade de } \\
\text { informações }\end{array}$ & & \\
\hline & & $\begin{array}{l}\text { Orçamentos } \\
\text { interorganizacionais }\end{array}$ & & \\
\hline & & Custeio alvo & & Estabelecimento de \\
\hline Hierárquica & $\begin{array}{l}\text { mercado capazes de } \\
\text { inviabilizar o cumprimento } \\
\text { dos contratos e, } \\
\text { diferentemente da estrutura } \\
\text { de mercado, institucionaliza } \\
\text { compromissos a longo prazo. }\end{array}$ & $\begin{array}{l}\text { Orçamentos } \\
\text { interorganizacionais }\end{array}$ & $\begin{array}{l}\text { Foco na redução } \\
\text { de custos. }\end{array}$ & $\begin{array}{l}\text { compromissos para os } \\
\text { agentes integrantes da } \\
\text { cadeia, a partir de metas } \\
\text { estipuladas, remetendo } \\
\text { à institucionalização de } \\
\text { compromissos a longo prazo, } \\
\text { descrito na estrutura da ECT. }\end{array}$ \\
\hline
\end{tabular}

Quadro 4. Relação entre mecanismos disciplinadores da GCl e mecanismos de governança da ECT

Nota: elaborado pelos autores.

Desse modo, percebe-se uma relação entre os mecanismos disciplinadores da GCI e os mecanismos de governança abordados na ECT, o que mostra que a GCI, artefato relativamente recente da Gestão Estratégica de Custos, sofre influência da teoria dos Custos de Transação, quando se trata de mecanismos para salvaguardar relacionamentos de parceria na cadeia de valor.

Vale destacar, por fim, que Donada e Nogatchewsky (2006) avaliaram como os compradores controlam os fornecedores em situações de assimetria nas relações interorganizacionais sob a perspectiva da ECT. Pela perspectiva da ECT, há necessidade de contratos compreensíveis para reger as transações entre as partes, o que, mais uma vez, denota sua relação com a GCI. Mas, em sentido oposto, uma das conclusões dos autores foi que fornecedores dominantes não aceitam contratos que intervenham diretamente na relação, e, como consequência, não há mecanismos para controle de suas transações.

Uma vez concluída a análise e constata a relação motivo desta investigação, entende-se que a continuidade da pesquisa é avançar do ensaio teórico para uma pesquisa de campo para comprovar se, também na prática, a existência de relação entre os mecanismos disciplinadores da GCI e os de governança da ECT se confirma. Neste caso, a estrutura de análise aqui utilizada poderá servir de base para a investigação em campo.

Assim, caso comprovada também na prática a existência da relação, entende-se que se estará dando um passo importante no campo dos relacionamentos interorganizacionais, por meio da integração de elementos conceituais advindos de artefatos diferentes, bem como pela melhoria nos níveis de controle das relações contratuais e redução dos custos de transação. 


\section{Considerações finais e sugestões para futuras pesquisas}

O objetivo do presente trabalho consistiu em verificar se os mecanismos disciplinadores presentes na estrutura conceitual da GCI estão relacionados aos mecanismos de governança previstos pela ECT, bem como os instrumentos para salvaguardar relações contratuais.

Segundo a estrutura conceitual abordada pela ECT, não existe uma estrutura de governança que seja ideal para todas as transações, sendo que a melhor estrutura de governança a ser utilizada varia em função das características da transação envolvida, sendo requeridos diversos instrumentos para coordenação dessas transações (Peres, 2007). Ademais, inserem-se às relações contratuais objeto dos mecanismos de governança a possibilidade de comportamentos oportunistas dos agentes, adicionando risco e maiores custos de transação, sendo necessários mecanismos que busquem conter tais disfunções.

A GCI aborda a coordenação das atividades inerentes às relações contratuais existentes, entre as empresas que compõem uma cadeia de valor, buscando a redução de custos ao longo de toda a cadeia (Hoffjan \& Kruse, 2006). Porém, para tanto, faz-se necessária a utilização de mecanismos que busquem conduzir os relacionamentos entre os agentes ao longo da cadeia, como os mecanismos disciplinadores previstos pela GCI.

Desse modo, a ECT utiliza-se de mecanismos de governança para diminuir os custos de transação das relações contratuais (Williamson, 1996), e, em linha, os mecanismos disciplinadores da GCI buscam reger as relações ao longo da cadeia, diminuindo a possibilidade de comportamentos disfuncionais e custos de transação (Souza \& Rocha, 2009). Assim, encontrou-se como resultados que os mecanismos de governança utilizados pela ECT estão relacionados aos mecanismos disciplinadores da GCI, ou seja, os mecanismos disciplinadores utilizados pela GCI vão ao encontro dos mecanismos de governança da ECT, uma vez que apresentam relação em diversos dos mecanismos analisados.

Como implicações dos resultados encontrados, destaca-se a função da GCI enquanto mecanismo de coordenação de contratos existentes. Segundo Sunder (1997), a Contabilidade, por meio de seus diversos instrumentos, possui a função de oferecer mecanismos para a coordenação dos contratos. Desse modo, nota-se que a GCI cumpre a sua função de mecanismo para coordenação contratual, enquanto elemento da Contabilidade de Custos. Ainda, conforme previsto pela ECT, os comportamentos oportunistas e a racionalidade limitada dos agentes são inerentes às relações ocorridas ao longo da cadeia, requerendo mecanismos para gerir essas relações e, consequentemente, reduzir os custos de transação (Souza \& Rocha, 2009; Zylberstajn, 1995). Como os mecanismos disciplinadores da GCI encontram-se relacionados aos elementos das estruturas da governança da ECT, eles podem ser utilizados para gestão das relações contratuais ao longo da cadeia, reduzindo o custo de transação, suprindo a demanda por esse tipo de mecanismos (Miranda et al., 2010; Souza \& Rocha, 2009; Zylberstajn, 1995).

Assim, este estudo faz avançar o conhecimento teórico ao abordar a existência de relacionamentos entre mecanismos de uma teoria que busca verificar a forma como ocorrem as transações, considerando um dado ambiente e a estrutura de um artefato utilizado para a gestão de custos em diversas relações ao longo de uma cadeia. A identificação dessa relação evidencia a possibilidade de a GCI utilizar os mecanismos já consolidados pela ECT, com o intuito de aumentar a probabilidade de sucesso na sua implantação e uso.

Diante disso, uma proposta concreta de continuidade desta pesquisa consiste em investigar, no campo, ou seja, na realidade dos relacionamentos interorganizacionais, se esta relação se confirma. Para tanto, a estrutura de análise aqui utilizada pode ser aplicada como ponto de partida em uma investigação empírica. Entende-se que, se constatada também a relação na prática, e, se constatada a redução dos custos de transação por meio da utilização dos mecanismos da GCI, a contribuição pretendida por este estudo estará alcançada. Recomenda-se, por fim, que futuros estudos busquem expandir a estrutura conceitual que embasou as análises para verificar possíveis relações entre a ECT e os demais mecanismos utilizados pela GCI (mecanismos incentivadores e capacitores) ou, ainda, analisar a possível incorporação de outros mecanismos já previstos na ECT, mas que ainda não foram abordados na GCI. 


\section{Referências}

Agndal, H., \& Nilsson, U. (2010). Different open book accounting practices for different purchasing strategies. Management Accounting Research, 21(3), pp. 147-166. doi:10.1016/j.mar.2010.04.001

Aguiar, A. B., Rezende, A. J. \& Rocha, W. (2008). Uma Análise da Complementariedade entre Gestão Interorganizacional de Custos e Open-Book Accounting. Base - Revista de Administração e Contabilidade da Unisinos, 5(1), pp. 66-76.

Arrow, K. J. (1974). The limits of organization. New York. Norton \& Company.

Arrow, K. J. (1969). The Organization of economic activity: issues pertinent to the choice of market versus nonmarket allocation. In: The Analysis and evaluation of public expenditure. Cambridge: Harvard University Press.

Arruda, A. G. S. (2014). Estruturas de governança em redes de cooperativas de crédito sob a ótica da teoria dos custos de transação: um estudo comparativo entre cooperativas brasileiras e canadenses. Tese de Doutorado, Universidade Municipal de Caetano do Sul, São Caetano do Sul, SP, Brasil. Recuperado de http: http://www.uscs.edu.br/posstricto/administracao/teses/2014/pdf/TESE_PPGA_ ALESSANDRO_G_S_ARRUDA.pdf

Bhimani, A., Souza, B. C., \& Rocha, W. (2011). Inter-organizational cost management in a Brazilian context. Cost Management, 25(6), pp. 5-16.

Brito, J. (1994). Redes de firmas e eficiência técnico-produtiva: uma análise crítica da abordagem dos custos de transação. Anais do Encontro Nacional de Economia da Anpec, Florianópolis, SC, Brasil, 22.

Camacho, R. R. (2010). Fatores condicionantes da gestão de custos interorganizacionais na cadeia de valor de hospitais privados no Brasil: uma abordagem à luz da Teoria da Contingência. Tese de doutorado, Universidade de São Paulo, SP, Brasil. Recuperado de http://www.teses.usp.br/teses/disponiveis/12/12136/ tde-22012011-164307/pt-br.php

Coad, A. F., \& Cullen, J. (2006). Inter-organisational cost management: Towards an evolutionary perspective. Management Accounting Research, 17(4), pp. 342-369. doi:10.1016/j.mar.2006.02.003

Coase, R. H. (1937). The nature of the firm. Economica, 4(16), pp. 386-405. DOI: 10.1111/j.1468-0335.1937. tb00002.x

Coase, R. H. (1959). The federal communications commission. Journal of law and economics, 2, pp. 1-40.

Cooper, R. \& Slagmulder, R. (1997). Target costing and value engineering. Portland: Productivity Press, IMA Foundation for Applied Research.

Cooper, R., \& Slagmulder, R. (1999). Develop profitable new products with target costing. Sloan Management Review, 40(4), pp. 22-33.

Cooper, R., \& Slagmulder, R. (2003). Interorganizational costing. Part II. Cost Management. 17(5), pp. 12-24.

Dekker, H. C. (2003). Value chain analysis in interfirm relationships: a field study. Management accounting research, 14(1), pp.1-23. doi:10.1016/S1044-5005(02)00067-7

Donada, C., \& Nogatchewsky, G. (2006). Vassal or lord buyers: How to exert management control in asymmetric interfirm transactional relationships?. Management Accounting Research, 17(3), pp.259-287. doi:10.1016/j.mar.2006.06.002

Faria, A., Soares, I., Rocha, W., \& Rossi, G. (2013). A prática da gestão de custos interorganizacionais em uma montadora de veículos na Região do Grande ABC. Revista Brasileira de Gestão de Negócios, 15(49), 617-638.

Farina, E. M. M. Q. (1999). Competitividade e coordenação de sistemas agroindustriais: um ensaio conceitual. Gestão \& Produção, 6(3), pp. 147-161. 
Hoffjan, A., \& Kruse, H. (2006). Open book accounting in supply chains-When and how is it used in practice? Journal of cost management, 20(6), pp. 40-47.

Iudícibus, S. D., \& Lopes, A. B. (2004). Teoria avançada da contabilidade. São Paulo: Atlas.

Kajüter, P., \& Kulmala, H. I. (2005). Open-book accounting in networks: Potential achievements and reasons for failures. Management Accounting Research, 16(2), pp. 179-204. doi:10.1016/j.mar.2005.01.003

Martins, G. A. (2000). Manual para elaboração de monografias e dissertações. São Paulo: Atlas.

Menard, C. (2004). The economics of hybrid organizations. Journal of Institutional and Theoretical Economics, pp.345-376. doi: http://dx.doi.org/10.1628/0932456041960605

Miller, G. J. (1992). Managerial dilemmas: The political economy of hierarchy. Cambridge - UK: Cambridge University Press.

Miranda, W. F., Mendes, A. C. A., Souza, G. J. P., \& Zuccolotto, R. (2010). A economia dos custos de transação através do desenvolvimento da reputação favorável. Anais do Congresso USP de Controladoria e Contabilidade, São Paulo, SP, Brasil, 10.

Mouritsen, J., Hansen, A., \& Hansen, C. Ø. (2001). Inter-organizational controls and organizational competencies: episodes around target cost management/functional analysis and open book accounting. Management Accounting Research, 12(2), pp.221-244. doi:10.1006/mare.2001.0160

Muniz, G. P., Aquino, A. C. B., \& Pagliarussi, M. S. (2007). Mecanismos de governança na terceirização dos serviços de tecnologia da informação: uma survey em empresas do Espírito Santo. Anais do Encontro de Estudos em Estratégia, São Paulo, SP, Brasil, 3.

Peres, U. D. (2007). Custos de transação e estrutura de governança no setor público. Revista Brasileira de Gestão de Negócios, 9(24), pp. 15-30.

Porter, M. E. (1989). Vantagem competitiva - criando e sustentando um desempenho superior. Rio de Janeiro: Campus.

Rocha, W. F. D., Jr.; Carvalheiro, E. M., Staduto, J. A., \& Opazo, M. A. U. (2008). Avaliação de contratos: uma abordagem utilizando a Análise Fatorial de Correspondência. Revista de Economia e Sociologia Rural, 46(2), pp. 455-480.

Rocha, W., \& Borinelli, M. L. (2007). Análise estratégica de cadeia de valor: um estudo exploratório do segmento indústria-varejo. Revista Contemporânea de Contabilidade, 4(7), pp. 145-165.

Santos, A. R. (1999). Metodologia Científica: a construção do conhecimento. (6a ed.). Rio de Janeiro: DP\&A Editora.

Severino, A. J. (2007). Metodologia do trabalho científico. (23a ed.). São Paulo: Cortez.

Shank, J. K., \& Govindarajan, V. (1993). What" drives" cost? A strategic cost management perspective. Advances in Management Accounting, 2, pp. 27-45.

Slagmulder, R. (2002). Managing costs across the supply chain. In Seuring, S. \& Goldbach, M. (Eds.). Cost management in supply chains. pp. 75-88. Heidelberg, Physica-Verlag.

Souza, B. C. D. (2008). Fatores condicionantes da gestão de custos interorganizacionais. Dissertação de Mestrado, Universidade de São Paulo, SP, Brasil. Recuperado de http://www.teses.usp.br/teses/disponiveis/12/12136/tde-07042008-225007/pt-br.php

Souza, B. C., \& Rocha, W. (2008). Fatores Condicionantes da Gestão de Custos Interorganizacionais. Anais do Congresso USP de Controladoria e Contabilidade, São Paulo, SP, Brasil, 8.

Souza, B. C., \& Rocha, W. (2009). Gestão de custos interorganizacionais. São Paulo: Atlas.

Sunder, S. (1997). Theory of Accounting and Control. Cincinnati, OH: Thomson Press. 
Vergara, S. C. (2003). Projetos e relatórios de pesquisa em administração. (4a ed.). São Paulo: Atlas.

Vosselman, E., \& Meer-Kooistra, J. V. (2009). Accounting for control and trust building in interfirm transactional relationships. Accounting, Organizations and Society, 34(2), pp.267-283. doi:10.1016/j. aos.2008.04.002

Williamson, O. E. (1975). Market and Hierarchies: Analysis and Antitrust Implications. New York: The Free Press.

Williamson, O. E. (1981). The modern corporation: origins, evolution, attributes. Journal of economic literature, 19(4), pp. 1537-1568.

Williamson, O. E. (1985). The Economic institutions of capitalism: firms, markets, relational contracting. London: Macmillan Free Press.

Williamson, O. E. (1996). The mechanisms of governance. New York: Oxford University Press.

Windolph, M., \& Möller, K. (2012). Open-book accounting: Reason for failure of inter-firm cooperation? Management Accounting Research, 23(1), pp. 47-60. doi:10.1016/j.mar.2011.07.001

$\mathrm{Xu}, \mathrm{C}$. (2011). The Implementation Framework and Path Research of Interorganizational Cost Management in Supply Chain. Anais Annual International Conference on Management Science \& Engineering, Roma, Itália, 18.

Zylbersztajn, D. (1995). Estruturas de governança e coordenação do agribusiness: uma aplicação da nova economia das instituições. Tese de Livre Docência, Universidade de São Paulo, SP, Brasil. Recuperado de http://200.144.188.9/PortalFEA/Repositorio/616/Documentos/Tese_Livre_Docencia_DZ.pdf

Zylbersztajn, D. (2000). Economia das Organizações. In Zylbersztajn, D. \& Neves, M. F. (Org.) Economia e gestão dos negócios agroalimentares: indústria de alimentos, indústria de insumos, produção agropecuária, distribuição. Cap. 2, pp. 23-38. São Paulo: Pioneira. 